\title{
AHP IN TREND - CHANGED FORECASTING
}

\author{
Chang Q. Jiang, Ph.D \\ The College of West Virginia \\ Beckley, WV 25802
}

\begin{abstract}
SUBTRACT
Trend-change and changing judgment appear in many cases of forecasts. The purpose of this paper is to use the AHP as a method to structure a trend-changed forecast. In this analysis, a dynamic priority model of AHP is applied to the forecast and evaluation of teaching load of the College of West Virginia when changing judgment is a concern.
\end{abstract}

\section{Introduction}

The College of West Virginia (CWV) is using a planning process to set the course of action for meeting the needs of the next five years, and is positioning itself for the challenges of the 21 st century. The five-year plan is based on the review and assembly of a wide range of documents and statistical materials on the activities at the College of West Virginia in the past, at present, and projected into the future.

Some of the most significant decisions in the long-term planning are made on the basis of judgment forecasts [1]. Forecast of teaching load in the next five years is one of key issues, which provides a vision of what may be accomplished for the college looking to the long-term future of the institution. The CWV wants to predict the demand and sensitive level of teaching load for each of its five schools, to determine its investment level, work-force size, budgets, and facility capacity, among many other considerations. It is the accuracy of the forecast that will ultimately determine the degree of success of the planning, and the future of the institution.

As is the case with all long-term forecasts, that of CWV is based on a number of factors and broad assumptions believed to be reasonable. The forecast of teaching load involves in various aspects of judging process: the scope of the current 
academic program, recent enrollment trends, and the continuing efforts of the faculty to offer a variety 'of degrees and certificate programs in the areas that primarily have their focus on the local employment market.

It is conceivable that the experience and knowledge of CWV's administration and faculty play a key role in such forecast situation, where external factors have a significant impact, but not in a clearly defined way. For this reason, the Analytic Hierarchy Process (AHP) developed by Thomas L. Saaty [2] has been chosen as a basic method to incorporate human experience and expertise into the forecasting process, thus the factors can be assessed, a consensus of experts' individual judgment can be reached, and solutions to the forecasting problem can be found. To deal with trend change in the long-term forecast and planning, an AHP dynamic model has been employed eventually, which has been proved to be a great help to our efforts in handling the experts' judgment on the trend changes.

\section{The AHP Dynamic Priority Model}

The AHP is a useful tool to deal with unstructured problems, particularly ones involving forecasts. AHP breaks down an unstructured forecasting problem into its component factors, and reorganizes them into a hierarchical structure. Using a procedure of paired comparisons, it assesses the relative importance of each factor The final result is given in the form of a priority vector of the factors, which is the solution of the following eigenvalue problem,

$$
\mathrm{Aw}=\lambda_{\max } \mathrm{w}
$$

When the values of the factors change over time, the forecasting problem becomes an issue of the solution of eigenvalue in a time-dependent function as follows:

$$
A(t) w(t)=\lambda_{\max }(t) w(t)
$$

In such cases, the application of AHP' in forecasting is concerned with dynamic priorities. Saaty provided a judgment matrix of pairwise comparison for the dynamic priorities. The entries of the matrix can be selected from one of the following functions: 
1. $\mathrm{a}_{\mathrm{ij}}(\mathrm{t})=\mathrm{a}$

2. $a_{\mathrm{ijj}}(\mathrm{t})=\mathrm{at}+\mathrm{b}$

3. $a_{i j}(t)=a \ln (\mathrm{t}+1)+b$

4. $\mathrm{a}_{\mathrm{ij}}(\mathrm{t})=\mathrm{a} e^{\mathrm{bt}}+\mathrm{c}$

5. $a_{i j}(t)=a t^{2}+b t+c$

6. $a_{\mathrm{ij}}(\mathrm{t})=\mathrm{at} \mathrm{t}^{\mathrm{n}} \sin (\mathrm{t}+\mathrm{b})+\mathrm{c}$

7. $\mathrm{a}_{\mathrm{ij}}(\mathrm{t})=$ catastrophes

These functions represent the most common judgment on trend changes: constant, linear, logarithmic, exponential, rising to a maximum and declining; oscillating, and catastrophic. However according to the well-known Galios theory, an analytic solution of equation (2) is only available for the judgment matrices $A(t)_{n \times n}$ with $n<$ 5 .

$\mathrm{Xu}$ and Liu proposed a form of dynamic judgment matrix [3] which has no limitation to the number of its entries and is easy to use for searching the solution of changing judgment. This dynamic priority model of AHP was employed to solve. the forecasting problem presented in this paper. To explain the model, let us first introduce a definition of total consistency of the dynamic judgment matrix.

Definition A dynamic judgment matrix $A(t)=\left(a_{i j}\right)_{n \times n}$ is totally consistent at $\left[t_{0}, t_{l}\right]$, if

$$
a_{i j}(t)=a_{i k}(t) / a_{j k}(t) \quad\left(i, j, k=1,2, \ldots, n, t_{0} \leq t \leq t_{1}\right)
$$

For a totally consistent matrix $A(t),\left(t_{0} \leq t \leq t_{1}\right)$, we have

$$
A(t)=M(t) A\left(t_{0}\right) M^{-1}(t)
$$

where $M(t)=\operatorname{diag}\left(a_{i}(t)\right),(i,=1,2, \ldots, n), M\left(t_{0}\right)=I$ is an identity matrix, and $A\left(t_{0}\right)$ is the pairwise comparison matrix at the initial time $t_{0}$.

If $\mathrm{w}_{0}$ is the principal eigenvector of $A\left(t_{0}\right)$ corresponding to the principal eigenvalue $\lambda_{\max }$, and $\lambda_{\max }$ is also the principal eigenvalue of $\mathrm{A}(\mathrm{t})=\mathrm{M}(\mathrm{t}) \mathrm{A}\left(\mathrm{t}_{0}\right) \mathrm{M}^{-1}(\mathrm{t})$, then the solution of the eigenvalue problem (2) can be given in the following simple analytic form, 


$$
W(t)=M(t) W_{0}
$$

in which $W(t)$ is the principal eigenvector.

\section{Forecasting of Teaching Load of the College of West Virginia}

CWV's long-term forecasting is based on a number of broad assumptions. These assumptions are summarized as follows.

- The nation's economy will continue to grow during the period 1993-1998.

- The recovery of the West Virginia economy will depend in part on the retraining of the large work force of coal, now heavily unemployed. Likely to improve the economic situation in southern West Virginia is the development of government employment and the expansion of tourism as the New River National Gorge is developed.

- It is noted that eastern panhandle of West Virginia is growing in population, and that region of the state is likely to continue to grow as it becomes an urban extension of metropolitan Washington. The movement of branches of various Federal agencies to West Virginia is likely to stimulate further growth of service industries in the southern and eastern region of the state; however, it is assumed that educational improvements at every level will be required if those business and industries are to find in West Virginia the human resources necessary to fill expected jobs.

- Student demand for programs offered by CWV will continue to be focused on those professions that students perceive to guarantee them a reasonable chance of gainful employment. Demand for health sciences, business, computer information systems, and career oriented liberal arts education will be the top priority of students. Programs in business, health and public service will emerge as the primary focus for graduate education.

- Build into the College's planning the idea that CWV will play a leadership role in the development of business and industry in the College's service area.

- CWV will continue to develop new programs within the context of an expanded College mission that will serve the needs of the College's constituencies. 
It is with these broad assumptions in focus that the College of West Virginia presents the detailed projections required for its five year plan. The goal is for the plan to incorporate a series of new challenges -- academic, administrative, and financial -- that will keep the College of West Virginia on the cutting edge of new innovations in higher education while retaining mainstream expectations within the academy during the next five years and then on into the next century.

The factors of the forecasting model are described as follows. The strategic goal of the College of West Virginia is to meet the demand of education in the state. The teaching load offered by each of its five schools in the next five years plays a key role in the achievement of this goal. These schools are Business School, School of Technology, School of Arts, School of Science, and School of Health Science. The effect of teaching load of each school on the college's strategic goal is measured by its contribution to the number of degrees granted to the college's students each year. The degrees granted are classified into four major groups with focus on market demand: business degrees, computer and information systems degrees, health science degrees, and other degrees. The structure of the forecasting model is represented in the AHP form as in the following figure:

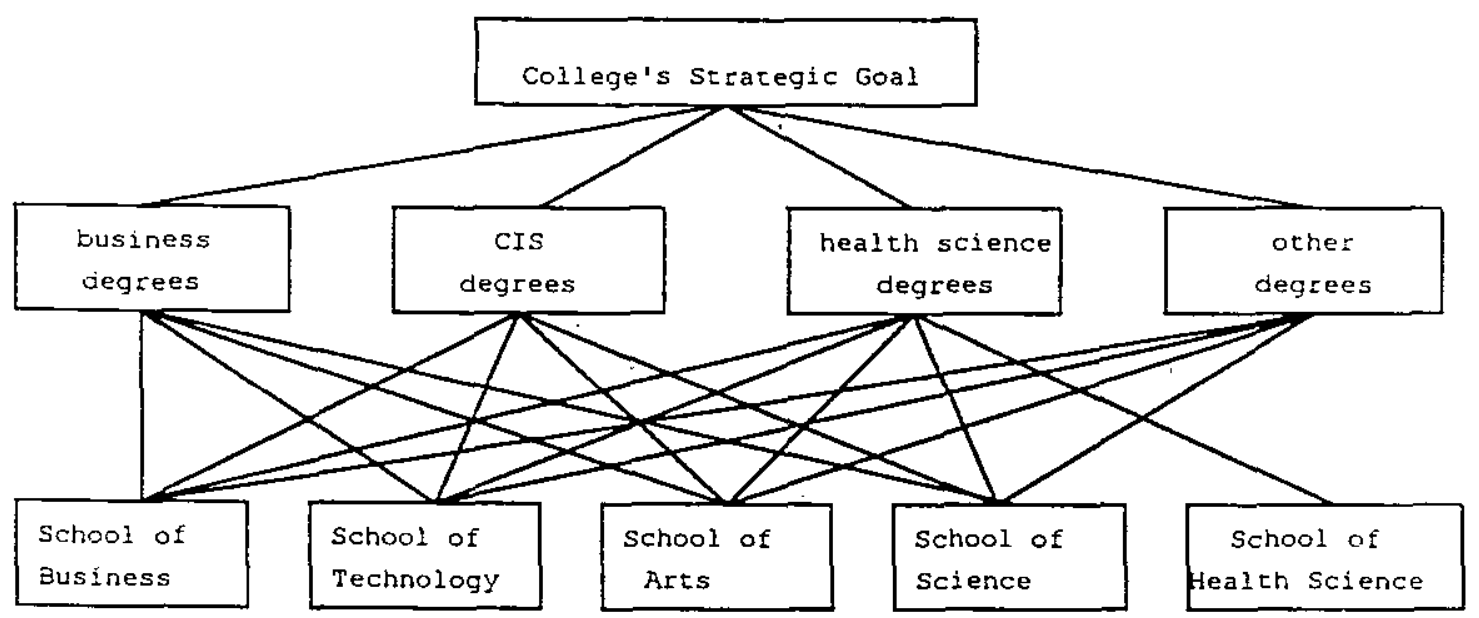

Figure. A hierarchical structure of forecast of teaching load of the College

The contribution of the major groups of granted degrees to the college's strategic goal can be regarded as a problem of dynamic priorities, since the demands and offer of these degrees are going to increase over time. On the basis of the information of twenty fastest growing occupations in the country [4] and projected job growth in 
the state [5], the numbers of granted degrees of the four major groups are estimated to increase in the next five years as follows: business degrees $25 \%$, CIS degrees $45 \%$, health science degrees $30 \%$, and other degrees $3 \%$. Assuming a linear growth, we have the following dynamic judgment matrices of pairwise comparisons of the factors,

\begin{tabular}{|c|c|c|c|c|c|}
\hline 1 & 1 & 2 & 1 & $1 / 2$ & 1 \\
\hline$A\left(t_{0}\right)=1$ & $1 / 2$ & 1 & $1 / 2$ & $1 / 4$ & | \\
\hline 1 & 1 & 2 & 1 & $1 / 2$ & 1 \\
\hline 1 & 2 & 4 & 2 & 1 & I \\
\hline 1 & \multicolumn{3}{|c|}{$1+0.25 t / 5$} & & 0 \\
\hline$M(t)=1$ & \multicolumn{5}{|c|}{$1+0.45 t / 5$} \\
\hline 1 & \multicolumn{5}{|c|}{$\mathrm{I}+0.3 \mathrm{t} / 5$} \\
\hline 1 & 0 & & & $1+0$ & $03 t / 5$ \\
\hline
\end{tabular}

The solution of this eigenvalue problem is given by,

$$
\mathrm{w}_{0}=\left(\begin{array}{llll}
0.222 & 0.111 & 0.222 & 0.444
\end{array}\right)^{\mathrm{T}} \quad \mathrm{IR}=0.001
$$

Then from (5), the dynamic priority vector $w(t)$ is obtained,

$$
\begin{aligned}
& w(t)=M(t) w_{0} \\
& =(0.222(1+0.25 t / 5) \quad 0.111(1+0.45 t / 5) \quad 0.222(1+0.3 t / 5) \quad 0.444(1+0.03 t / 5))^{\mathrm{T}}
\end{aligned}
$$

After a thorough study of the degree courses offered by each school, the following assessment has also been made of the teaching load contribution of each school. The matrices giving these judgments are, respectively 


\begin{tabular}{|c|cccc|}
\hline Business degrees & $\mathrm{C}_{1}$ & $\mathrm{C}_{2}$ & $\mathrm{C}_{3}$ & $\mathrm{C}_{4}$ \\
\hline $\mathrm{C}_{1}$ & 1 & 4 & 5 & 6 \\
$\mathrm{C}_{2}$ & $1 / 4$ & 1 & 2 & 2 \\
$\mathrm{C}_{3}$ & $1 / 5$ & $1 / 2$ & 1 & 1 \\
$\mathrm{C}_{4}$ & $1 / 6$ & $1 / 2$ & 1 & 1 \\
\hline
\end{tabular}

$\mathrm{w}_{1}=\left(\begin{array}{llll}0.613 & 0.185 & 0.104 & 0.099\end{array}\right)^{\mathrm{T}} \quad \mathrm{IR}=0.008$

\begin{tabular}{|c|cccc|}
\hline CIS degrees & $\mathrm{C}_{1}$ & $\mathrm{C}_{2}$ & $\mathrm{C}_{3}$ & $\mathrm{C}_{4}$ \\
\hline $\mathrm{C}_{1}$ & 1 & $1 / 3$ & 2 & 1 \\
$\mathrm{C}_{2}$ & 3 & 1 & 5 & 3 \\
$\mathrm{C}_{3}$ & $1 / 2$ & $1 / 5$ & 1 & $1 / 2$ \\
$\mathrm{C}_{4}$ & 1 & $1 / 3$ & 2 & 1 \\
\hline
\end{tabular}

$\mathrm{W}_{2}=\left(\begin{array}{llll}0.185 & 0.532 & 0.097 & 0.185\end{array}\right)^{\mathrm{T}} \quad \mathrm{IR}=0.002$

\begin{tabular}{|c|ccccc|}
\hline $\begin{array}{c}\text { Health science } \\
\text { degrees }\end{array}$ & $\mathrm{C}_{1}$ & $\mathrm{C}_{2}$ & $\mathrm{C}_{3}$ & $\mathrm{C}_{4}$ & $\mathrm{C}_{5}$ \\
\hline $\mathrm{C}_{1}$ & 1 & 1 & 1 & $1 / 2$ & $1 / 5$ \\
$\mathrm{C}_{2}$ & 1 & 1 & 1 & $1 / 2$ & $1 / 5$ \\
$\mathrm{C}_{3}$ & 1 & 1 & 1 & $1 / 2$ & $1 / 5$ \\
$\mathrm{C}_{4}$ & 2 & 2 & 2 & 1 & $1 / 3$ \\
$\mathrm{C}_{5}$ & 5 & 5 & 5 & 3 & 1 \\
\hline
\end{tabular}

$$
\mathrm{w}_{3}=\left(\begin{array}{lllll}
0.099 & 0.099 & 0.099 & 0.191 & 0.513
\end{array}\right)^{\mathrm{T}} \quad \mathrm{IR}=0.001
$$

\begin{tabular}{|c|cccc|}
\hline Other degrees & $\mathrm{C}_{1}$ & $\mathrm{C}_{2}$ & $\mathrm{C}_{3}$ & $\mathrm{C}_{4}$ \\
\hline $\mathrm{C}_{1}$ & 1 & $1 / 2$ & $1 / 3$ & $1 / 4$ \\
$\mathrm{C}_{2}$ & 2 & 1 & $1 / 2$ & $1 / 2$ \\
$\mathrm{C}_{3}$ & 3 & 2 & 1 & 1 \\
$\mathrm{C}_{4}$ & 4 & 2 & 1 & 1 \\
\hline
\end{tabular}

$$
\mathrm{W}_{4}=\left(\begin{array}{llll}
0.100 & 0.185 & 0.345 & 0.370
\end{array}\right)^{\mathrm{T}} \quad \mathbb{R}=0.004
$$


As above, a priority vector is derived from each matrix. They are, respectively, the four columns of the following matrix,

$$
\left(w_{1} w_{2} w_{3} w_{4}\right)
$$

This matrix is then multiplied by the dynamic priority vector $w(t)$ to yield the following series of composite priority vectors in Table 1 , which measuring the impact of teaching load of each school on the College's goal over the next five years.

Table 1 The relative importance of teaching load of each school

\begin{tabular}{|c|l|l|l|l|l|}
\hline Schools & $\mathbf{1 9 9 4}$ & $\mathbf{1 9 9 5}$ & $\mathbf{1 9 9 6}$ & $\mathbf{1 9 9 7}$ & $\mathbf{1 9 9 8}$ \\
\hline Business & 0.225 & 0.227 & 0.228 & 0.230 & 0.231 \\
\hline Technology & 0.206 & 0.207 & 0.209 & 0.210 & 0.211 \\
\hline Arts & 0.206 & 0.203 & 0.200 & 0.197 & 0.195 \\
\hline Science & 0.247 & 0.244 & 0.242 & 0.240 & 0.238 \\
\hline Health Science & 0.116 & 0.119 & 0.121 & 0.123 & 0.125 \\
\hline
\end{tabular}

We have now predicted the rank of schools of the CWV on a ration scale according to their overall teaching load impact. The results of the forecast indicate that the overall priorities of the Business School, the School of Technology and the School of Health Science are to increase compared with that of the School of Arts and the School of Science. It draws our attention in the five-year plan to allocate more resources into the first three schools to support their further development.

\section{Conclusion}

In this paper, a practical use of the AHP to trend-changed forecasting has been presented. A dynamic priority model of AHP was successfully applied to the forecast and evaluation of teaching load of the CWV's five schools when changing judgment is a concern. The AFIP-derived ranking has helped the College to predict its schools' priority weight in the long-term plan. 


\section{References}

1. A Five-Year Action Plan for the College of West Virginia, The College of West Virginia, 1994.

2. Saaty, T. L., The Analytic Hierarchy Process, McGraw-Hill, 1980.

3. Xu Shubo and Liu Bao, "The New Dynamic Priorities Model and an Analysis of China's Energy Strategy for the Future", The 7th International Conference on MCDM, Kyoto, Japan, 1986.

4. "Projected Job Growth", WV Service and Delivery Areas Annual Planning Information, 1994.

5. "Twenty Fastest Growing Occupations", Monthly Labor Review, Bureau of Labor Statistics, U.S. Department of Labor, November, 1991. 